OPEN ACCESS

Edited by:

Jean F. Regal,

University of Minnesota, United States

Reviewed by:

Ulrike Kemmerling,

University of Chile, Chile

Nardhy Gomez-Lopez,

Wayne State University, United States

Nabila Jabrane-Ferrat,

INSERM U1043 Centre de

Physiopathologie de Toulouse

Purpan, France

*Correspondence:

Roser Vento-Tormo

rv4@sanger.ac.uk

Specialty section:

This article was submitted to

Molecular Innate Immunity,

a section of the journal

Frontiers in Immunology

Received: 22 May 2020

Accepted: 29 July 2020

Published: 10 September 2020

Citation:

Hoo R, Nakimuli $A$ and Vento-Tormo $R$ (2020) Innate Immune Mechanisms to

Protect Against Infection at the

Human Decidual-Placental Interface.

Front. Immunol. 11:2070

doi: 10.3389/fimmu.2020.02070

\section{Innate Immune Mechanisms to Protect Against Infection at the Human Decidual-Placental Interface}

\author{
Regina Hoo ${ }^{1,2}$, Annettee Nakimuli ${ }^{1,3}$ and Roser Vento-Tormo ${ }^{1,2 *}$ \\ ${ }^{1}$ Wellcome Sanger Institute, Cambridge, United Kingdom, ${ }^{2}$ Centre for Trophoblast Research, University of Cambridge, \\ Cambridge, United Kingdom, ${ }^{3}$ Department of Obstetrics and Gynecology, School of Medicine, Makerere University, \\ Kampala, Uganda
}

During pregnancy, the placenta forms the anatomical barrier between the mother and developing fetus. Infectious agents can potentially breach the placental barrier resulting in pathogenic transmission from mother to fetus. Innate immune responses, orchestrated by maternal and fetal cells at the decidual-placental interface, are the first line of defense to avoid vertical transmission. Here, we outline the anatomy of the human placenta and uterine lining, the decidua, and discuss the potential capacity of pathogen pattern recognition and other host defense strategies present in the innate immune cells at the placental-decidual interface. We consider major congenital infections that access the placenta from hematogenous or decidual route. Finally, we highlight the challenges in studying human placental responses to pathogens and vertical transmission using current experimental models and identify gaps in knowledge that need to be addressed. We further propose novel experimental strategies to address such limitations.

\section{Keywords: innate immunity, uterine-placental interface, trophoblast, decidua, vertical transmission}

\section{INTRODUCTION}

The human placenta is the temporary extra-embryonic organ that is present only during pregnancy and is the anatomical boundary between the mother and fetus. It has a range of functions including transport of nutrients and gases, and hormonal production (1). The placenta forms a physical, selective barrier between the maternal and fetal circulations, preventing transfer of pathogens. The uterine mucosal lining, the endometrium, is transformed into the decidua during early pregnancy (2). A range of innate immune mechanisms can respond to pathogens in both the decidua and the placenta $(3,4)$. The maternal-fetal interface is a protective barrier against pathogens, but some pathogens can transfer from the mother to fetus by different routes and cause fetal infection $(3,4)$.

Vertical transmission during pregnancy can occur on distinct boundaries between the mother and the fetus: (i) the intervillous space (IVS), where placental villi is in direct contact with the maternal blood, (ii) the implantation site or decidua basalis, where maternal cells are in direct contact with the invading fetal trophoblast, and (iii) the fetal membranes, which are in direct contact with the uterine cavity (5). Defense mechanisms in the cervix, such as the production of mucus and antimicrobial peptides (AMP), limit ascending infection from pathogens present in the lower genital tract, that otherwise may access the uterine cavity (6). However, some pathogens can escape antimicrobial strategies at the cervix and ascend to the uterus, where they can bypass the fetal membranes and lead to the inflammation of the membranes- also known as chorioamnionitis- and infection of the amniotic fluid $(7,8)$. Pathologic and immune features of chorioamnionitis and 
intra-amniotic infection are generally associated with bacterial invasion and inflammation [refer to $(8,9)$ for a comprehensive review on these mechanisms]. Here, we focus on infections and innate immune mechanisms at the uterine-placental interfacecases (i) and (ii) (Figure 1).

Infections at the uterine-placental interface are commonly associated with viruses, parasites and few bacteria (Table 1). Viral pathogens such as human cytomegalovirus (HCMV), Zika (ZIKV), and rubella virus are the most common vertically transmitted pathogens through the decidual-placental interface (Table 1) $(26,27)$. Non-viral pathogens, such as Toxoplasma gondii and Listeria monocytogenes, can cross the placental barrier via cell-to-cell transmission (Table 1) $(28,29)$. Fetal infection can result in various forms of congenital anomalies in humans (Table 1). Understanding the pathogenic mechanisms used by infectious agents is central to preventing vertical transmission and controlling infection during pregnancy.

How the innate immune cells and mechanisms in the placenta and the uterus recognize and respond to protect both the fetus and mother remains controversial due to technical and ethical constraints. However, there are several different models currently used to interrogate the uterine-placental interface in pregnancy. Firstly, mice are frequently used as a pregnancy model for infection. Although the murine models have provided important insights into the pathogenesis of various infection agents in the context of pregnancy, there are still limitations with this approach. The anatomy of placentation, length of gestation, and use of inbred strains, make extrapolation to humans problematic $(30,31)$. Secondly, a range of human trophoblast and choriocarcinoma cell lines are used as in vitro models for infection with pathogens. In contrast to the first trimester trophoblast in vivo, these cell lines do not recapitulate normal human trophoblast characteristics such as expression of the human leukocyte antigen (HLA) class I and methylation of ELF5 $(32,33)$. Thirdly, human primary placental explants are frequently used. The syncytium dies rapidly in these cultures and it is virtually impossible to standardize the types of villi sampled (30). Therefore, these in vitro experimental factors should be taken into careful consideration when interpreting studies of infection of trophoblast.

In this review, we cover the innate immune features of the decidual-placental interface throughout gestation. We identify the gaps in knowledge and highlight the limitations of current studies and experimental models. Finally, we discuss novel experimental strategies for understanding how infection affects pregnancy in humans.

\section{Physiology of the Placenta Throughout Gestation}

The trophoblasts of the placenta are the barrier between fetal and maternal tissues. They are derived from the trophectoderm, the outer layer of the blastocyst that forms an inner mononuclear layer with an outer primary syncytium following implantation (34). The trophoblast in contact with the maternal cells can be: (i) syncytiotrophoblast (SCT), a single layer multinucleated, syncytial layer formed by fusion of the underlying villous cytotrophoblast (VCT), and (ii) extravillous trophoblast (EVT), that invade from the cytotrophoblast shell and anchoring villi into the transformed maternal endometrium, the decidua (2).

The function of EVT is to transform the uterine spiral arteries so that maternal blood is delivered to the intervillous space at low pressure. The arteries are surrounded by interstitial EVT that destroys the smooth muscle cells of the arterial media, known as "fibrinoid" change $(35,36)$. Subsequently, endovascular EVT (eEVT) moves down the spiral arteries from the placentadecidua boundary (35). These eEVT form a plug of cells, limiting surges of arterial blood from damaging the delicate villi. EVT invasion transforms the arteries to support optimal regulation of blood flow into the placenta during fetal development (36). The plugs dissipate between 8 and 10 weeks of gestation when the full hemochorial circulation is established (37). Maternal blood then flows into the IVS, and establishes direct contact with the SCT allowing for proper nutrient and gas exchange between the mother and the fetus.

\section{HOFBAUER CELLS: THE TISSUE RESIDENT IMMUNE CELLS OF THE PLACENTA}

Hofbauer (HB) cells are fetal macrophages of the human placenta (38). HB cells can be detected in the placental villous stroma as early as 3 weeks post-conception and are present throughout pregnancy $(1,39)$. They are likely to have a variety of functions including control of villous remodeling and differentiation, hormonal secretion, and trophoblast turnover (1, 40). Several lines of evidence have led to the postulation that $\mathrm{HB}$ cells may have a role in infection during pregnancy. HB cells with ZIKV viral particles detected intracellularly have been shown $(41,42)$. Human immunodeficiency virus 1 (HIV-1) has also been detected in $\mathrm{HB}$ cells from first trimester infected placenta (43). Whether the HB cells can serve as a reservoir or limit virus replication is still unknown. Isolated $\mathrm{HB}$ cells from healthy term placenta show elevation of pro-inflammatory cytokines such as IL-6, MCP-1, IP-10, and IFN- $\alpha$ upon in vitro infection with ZIKV (44). HB cells from the first trimester placenta are also permissive for ZIKV infection and replication (23). However, this must be interpreted with caution because in vitro culture of $\mathrm{HB}$ cells do not entirely recapitulate the complexity of villous stromal microenvironment, such as presence of hormone and growth factors, all of which will influence the function and activity of $\mathrm{HB}$ cells (45).

\section{MATERNAL BLOOD AND SCT INTERFACE}

The SCT is the barrier between maternal blood and the placental core as it separates the IVS from the underlying fetal villous stroma. Blood-borne pathogens such as viruses and parasites can potentially be transmitted through the SCT barrier (Figure 1).

How can pathogens cross the SCT barrier and the VCT to infect the villous stroma? Although the SCT is an efficient barrier due to its stiff, highly dense actin cytoskeleton network and continuous membrane (46), the syncytium undergoes 


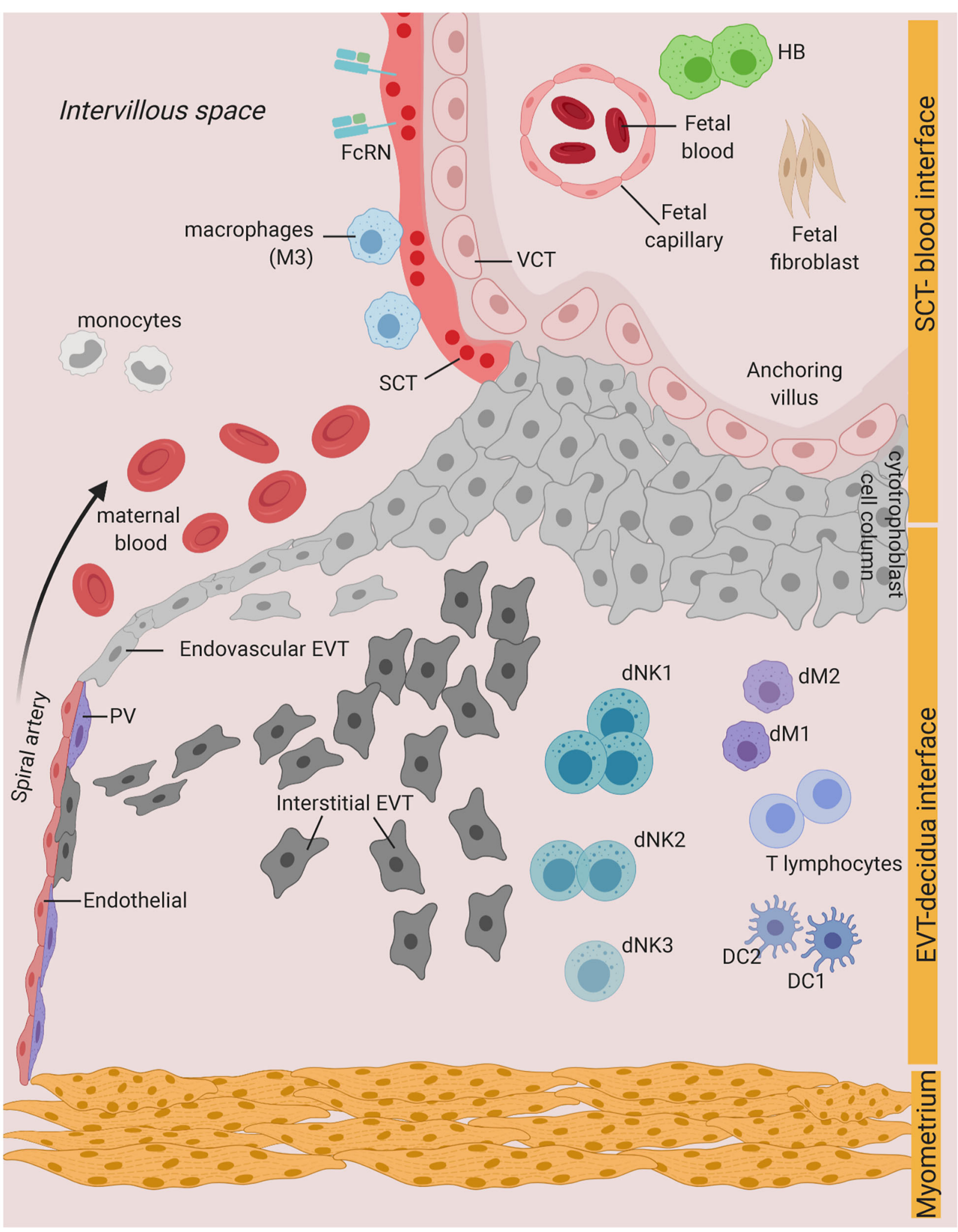

FIGURE 1 | Possible infection and vertical transmission route at the maternal-fetal interface. Illustration representing the anchoring placenta villi of early pregnancy, with onset of maternal blood circulation bathing the intervillous space. SCT-blood interface represents the SCT barrier exposed to maternal blood and immune cells. EVT-decidua interface represents the interface between EVT and maternal decidua cells. Major cell types of placenta trophoblast and decidua from Vento-Tormo et al (10) are represented. SCT, syncytiotrophoblast; VCT, villous cytotrophoblast; EVT, extravillous trophoblast; DC, dendritic cell; dNK, decidua Natural killer cells; dM, decidua macrophages; HB, Hofbauer cell; PV, perivascular cells; FcRN, neonatal Fc receptor. Figure is created by BioRender.com. 
TABLE 1 | Vertically transmitted pathogens with clinical evidence from natural human infection.

\begin{tabular}{llll}
\hline Species Lifestyle Life cycle and pathogenesis & $\begin{array}{l}\text { Clinical manifestations } \\
\end{array}$ & $\begin{array}{l}\text { Evidence of cellular } \\
\text { tropism in the human } \\
\text { placenta or decidua by } \\
\text { histology or PCR }\end{array}$
\end{tabular}

Chlamydia trachomatis Intracellular bacteria

Group B Streptococcus (Streptococcus agalactiae)

Listeria monocytogenes (Listeriosis)

Coxiella burnetii $(\mathrm{Q}$
fever)
Treponema pallidum

Toxoplasma gondii (Toxoplasmosis)

Trypanosoma cruzi (Chagas)

Intracellular and extracellular parasite

Herpes simplex virus 1, dsDNA virus 2 (HSV-1/2)

Human dsDNA virus cytomegalovirus(HCMV)

Rubella ssRNA virus

Parvovirus B19 ssDNA virus

Varicella zoster virus $\quad$ ssDNA virus (Chicken pox)

ZIKA virus (ZIKV) bacteria

extracellular bacteria Intracellular parasite
Formation of reticulate body inside host cell allows for rapid replication Conversion of reticulate body to elementary body inside host cell promotes the release of infectious bacteria to neighboring cell

Beta-hemolytic

Strong adherence to epithelial layer Able to form biofilm

Motile intracellular Utilize two bacterial surface proteins (internalin $A$ and $B$ ) to invade various non-phagocytic cell types Able to escape phagosome-mediated lysis and multiply rapidly in host cytoplasm Able to spread to adjacent cell through host cell actin polymerization

Intracellular Able to escape phagosome-mediated lysis

\section{in macrophage}

endothelial cells

Highly motile

Able to infect and replicate within various host cell types

Able to switch between non-motile (for replication) and motile state (for egress and invasion into new host cell)

Able to propagate in various host cells and Stillbirth, preterm labor escape

Progeny released by host cells are motile, and able to infect distal tissue or organs

Able to cross through skin lesions and epithelial mucosal cells

Poor antibody neutralization to viral glycoprotein D (gD)

Vertical transmission rate is very low

Easily transmitted through bodily fluid

Poor antibody neutralization to viral

glycoprotein B (gB)

Can establish lifelong latency in myeloid cells

Able to enter the lymphatic system from the respiratory tract

Can lead to a systemic infection

Viral capsid can evade host immune recognition

Spread through respiratory droplets Preferential tropism for human erythroid progenitor

Vertical transmission is very rare and only happens in primary infection

Mosquito borne infection transmitted from blood meal

Preferentially to invade blood monocytes preterm labor, blinding neonatal pneumonia

Ectopic pregnancy, stillbirth, Whole placenta, glandular epithelial cells, unidentified corneal injury in neonates, decidual cells

Neonatal GBS (sepsis and meningitis), preterm birth

Spontaneous abortion, stillbirth, preterm labor

Spontaneous abortion, preterm delivery, fetal death

Congenital syphilis

Placenta (unknown cell type)

Placenta (unknown cell type)

Congenital toxoplasmosis, stillbirth

Placenta trophoblast

SCT, villous stroma, placenta basal plate

Spontaneous abortion,

Decidua intrauterine growth restriction, preterm labor, neonatal herpes

Variable; neonatal neurodevelopmental damage and hearing loss

Significant birth defects, neonatal deafness, miscarriage

Fetus is usually unaffected, Whole placenta, placenta may result in severe fetal anemia

Congenital varicella syndrome, intrauterine growth restriction, low birth weight

Congenital fetal anomalies (microcephaly), miscarriage, stillbirth
Placenta basal plate and endothelial cells

VCT, decidua, amniotic membrane

villi

No evidence, but chronic villitis has been described

Whole placenta, amniotic epithelium, VCT, Hofbauer cells, decidual macrophages, decidual fibroblast 
continuous breaks or gaps and dynamic repair processes (47). Breaks in the syncytium could potentially lead to transmission of pathogens into the underlying VCT. Our recent work showed that a novel population of maternal macrophages (M3) is associated with the SCT in early pregnancy and might be involved in repairing the breaks in the syncytium (10). It is intriguing that M3 macrophages infected with intracellular pathogens could possibly gain access to the underlying VCT via the syncytial breaks (Figure 2).

Only a few viral entry receptors on the SCT are described. Notably, the SCT lacks expression of ZIKV entry receptors, Axl, and Tyro3 (48) and the HCMV entry co-receptor integrin $\alpha / \beta$ (49). This is further supported by the transcriptomic expression of viral receptors in placental cells $(10,50,51)$. Expression of surface receptors commonly used by ZIKV such as AXL and
HCMV such as NRP2 and PDGFRA are lowly expressed by the SCT (50). In addition, there is minimal co-expression of ACE2, the receptor gene for human severe acute respiratory syndrome coronavirus 2 (SARS-CoV-2), and TMPRSS2, the viral spike protein serine protease gene $(50,52)$. In line with this, there is no conclusive and direct evidence of vertical transmission of SARS$\mathrm{CoV}-2$ in a placenta from a healthy individual. There are some reports showing SARS-CoV-2 is predominantly localized at the SCT of the second trimester placenta $(53,54)$ and can lead to severe inflammatory infiltrate in the IVS (55). However, these findings are presented in a very small number of patients with severe disease or pre-existing pregnancy complications $(54,55)$.

Alternative transplacental mechanisms have been postulated at the syncytial barrier. Neonatal Fc receptor (FcRn) is expressed on the apical surface of the SCT and functions to selectively

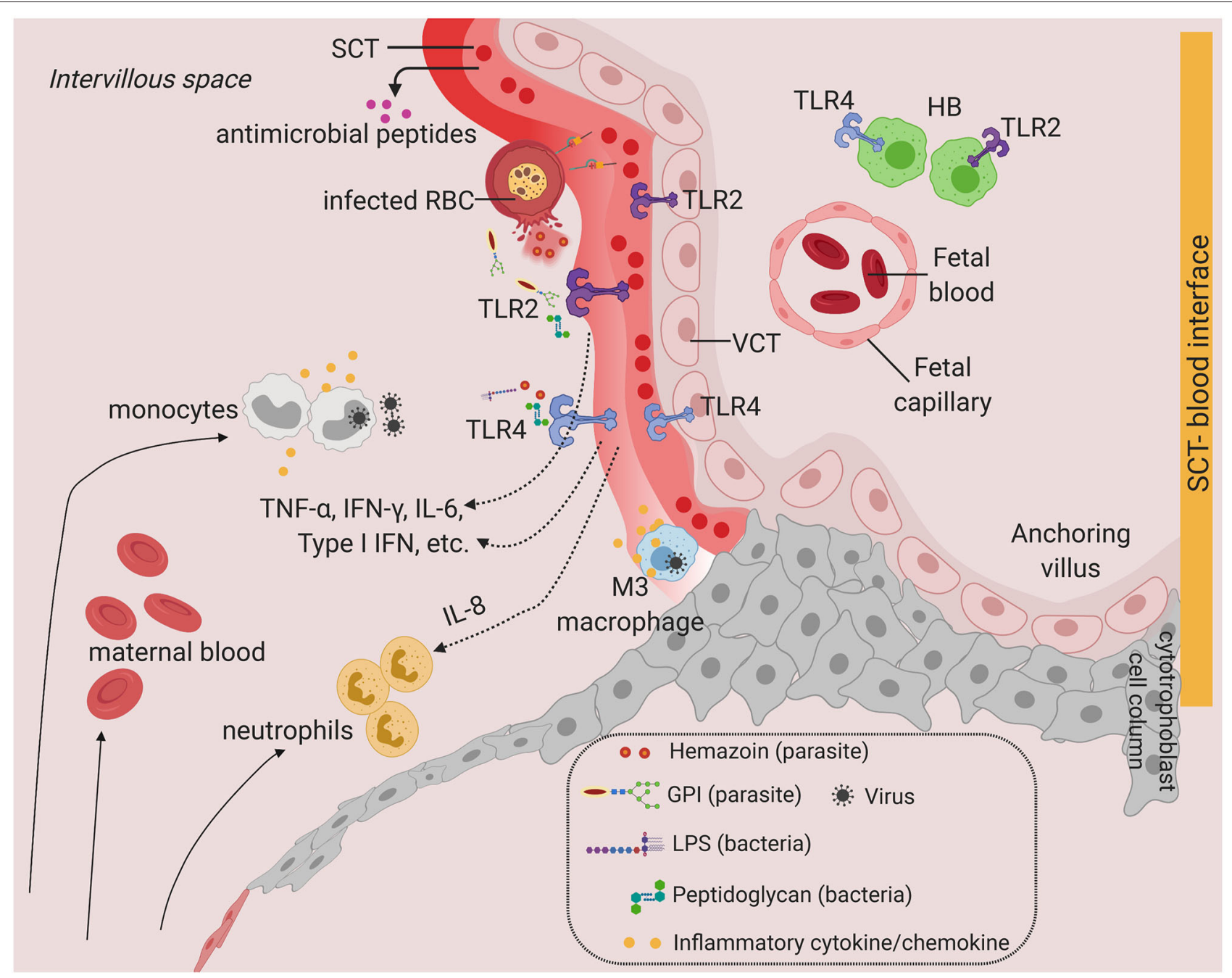

FIGURE 2 | Toll-like receptors and potential inflammatory response at the SCT-blood interface. Predominant TLRs found in the human placenta from early and term pregnancies. TLR2 and TLR4 are expressed in human placenta SCT, VCT, and in HB cells. Infiltration of infected maternal blood, infected immune cells, or release of pathogenic determinant such lipopolysaccharide (LPS), peptidoglycan, or parasite materials such as hemozoin or GPI (glycosylphosphatidylinositol) into the IVS will activate TLR-mediated signaling, leading to the production of a wide range of cytokines and chemokines. Severe infection is characterized by massive immune cell infiltration including monocytes and neutrophils from systemic circulation and overproduction of inflammatory cytokines upon TLR activation. This may lead to SCT inflammation and damage. SCT also secretes antimicrobial peptides as innate immune mechanisms. Figure is created by BioRender.com. 
transport maternal IgG (56). FcRn could be exploited by certain viruses to enter the placenta including ZIKV, HIV-1, and HCMV (19, 57, 58). Transferrin receptor 1 (TfR1) is expressed on the apical end of the SCT, and functions as the primary iron transporter into the basal side of the SCT to provide sufficient iron stores into fetal circulation (59). TfR1 has been associated with viral entry into a broad host cell range, including Hepatitis $\mathrm{C}$ virus $(60,61)$ suggesting a possible mechanism of viral transport across the SCT barrier. Some pathogens, although unable to cross the SCT barrier, can still adhere to the syncytium and cause further pathology. For instance, Plasmodium falciparum infected red blood cells can bind with high affinity to chondroitin sulfate A expressed on the SCT, resulting in local inflammation, syncytial breaks, and damage (62-64).

Although the SCT is an effective barrier to most pathogens, local inflammation, tissue damage, and FcRN or TfR1-mediated viral entry at the SCT can potentially allow pathogen to breach the syncytial barrier, giving opportunity for transmission from maternal blood into placental villi (Figure 2).

\section{MATERNAL DECIDUA AND EVT INTERFACE}

During the first trimester of pregnancy, fetal EVT invades deeply into the uterus. The decidua basalis, the region located at the implantation site, is populated at this time by a distinctive subset of innate lymphocytes, decidual Natural Killer cells (dNK), which constitute up to $70 \%$ of leukocytes. We have identified three major populations of $\mathrm{dNK}$ by single-cell RNA-sequencing with unique phenotypes and functions in early pregnancy (10). In addition, there are populations of decidual macrophages (dMs) ( 20\%), conventional dendritic cells (DCs) and small proportions of T cells ( $\sim 10-15 \%)$, whereas B cells, plasma cells, mast cells, and granulocytes are virtually absent (10) (Figure 1). The proportion of immune cells will vary throughout pregnancy, with an increase in the proportion of T cells at term (51).

Systemic infections will reach all organs including the decidua. Whether pathogens can also access the decidua via the cervix is still unclear. Chlamydia trachomatis, a common sexuallytransmitted intracellular bacteria, was detected in glandular epithelial cells and unidentified decidual cells in decidual biopsies (11). This suggests the possibility of infections ascending and spreading from cell-to-cell from the lower genital tract into endometrial glands and vascular endothelium. The decidua basalis is in close contact with fetal cells and the maternal vasculature (Figure 1). First trimester $\mathrm{dMs}$ and decidual stromal cells are susceptible to ZIKV infection and replication ex vivo (23). Hence, infection could possibly spread from infected maternal immune and non-immune cells at the decidua, into uninfected VCT in the columns of the anchoring villi, and finally into the fetal compartment. However, this is likely to be limited to certain microorganisms which are capable of cell-to-cell spread, have an intracellular host niche, and are able to escape host innate defense mechanisms (Table 1).

HCMV, the most common cause of congenital infection, is mostly reported to infect from the decidua $(11,65)$. Women with primary HCMV infection and first pregnancy are more likely to transmit the virus to their fetus, compared to multiparous women with previous infection and demonstrable antibodies (66-68). Low affinity maternal antibodies against HCMV correlate with higher viral loads detected in the decidua, whereas patients with intermediate to high neutralizing antibodies have minimal viral replication (65), suggesting that maternal immunity against HCMV reduces risk of vertical transmission. HCMV protein was also detected in a range of cells within the decidua including endothelial, decidual stromal cells, DCs and macrophages $(11,65)$, suggesting that that infected maternal leukocytes could initiate transmission through contact and infection of endothelial cells that line decidual blood vessels.

Despite the evidence of decidual infection, the mechanism of vertical transmission for HCMV is still in debate. dNKs have been proposed to play a protective role against HCMV infection through several mechanisms including modulation of their cytotoxic effector function (69) and the interactions between the killer-cell immunoglobulin receptors (KIRs) expressed by dNK and HLA molecules expressed in the infected cells (70, 71). Activating KIR2DS1 by dNKs has been demonstrated to be more cytolytic against HLA-C2 HCMV-infected maternal decidual stromal cells (70). Similar cytotoxic response was also observed when peripheral blood NK cells expressing KIR2DS1 were exposed to HCMV-infected fibroblasts (71). Hence, this implies that in the decidua, dNKs are capable of eliminating harmful infection depending on the combination of KIR/HLA interactions between $\mathrm{dNK}$ and infected cells. dNKs are also able to control HIV-1 infection in vitro through production of IFN- $\gamma$ (72). The role of $\mathrm{dNK}$ in controlling viral infection may protect against potential risk of vertical transmission from the decidua.

\section{TRANSMEMBRANE PATTERN RECOGNITION RECEPTORS: TOLL-LIKE RECEPTORS}

Pattern recognition receptors (PRR) are encoded in the germ-line and recognize specific, conserved pathogen-associated molecular patterns (PAMPs). These include Gram-negative bacteria lipopolysaccharide (LPS), Gram-positive bacteria lipoteichoic acids, lipoprotein, DNA, RNA, glucans, and peptidoglycans $(73,74)$. Pathogen recognition is not only an essential component of the innate immune response against infection, but also plays an important role in bridging the innate and adaptive systems by Toll-like receptors (TLR) activation of antigen presenting cells by up-regulation of major histocompatibility complex (MHC) and co-stimulatory molecules (75).

TLRs, the most studied family of PRR, are type I transmembrane proteins with large extracellular domains containing leucine-rich repeats that are expressed at the cell surface or intracellularly (76). Each TLR recognizes distinct PAMPs, leading to the activation of the transcription factor $\mathrm{NF}-\kappa \mathrm{B}$ and/or the interferon-regulatory factor (IRF) family, and the production of a wide range of cytokines and chemokines, 
including type I IFNs $(76,77)$. TLRs are expressed by immune cells (macrophages, DCs, and B cells) as well as non-immune cells (fibroblasts and epithelial cells) (74).

\section{TLRs at the Human Uterine-Placental Interface}

Expression of TLRs is dynamic and changes in response to different pathogens and cytokines (74). TLR2 (which recognizes bacterial proteoglycan) and TLR4 (which recognizes bacterial LPS) are the most well-studied, with immunohistochemical evidence of expression in healthy primary SCT at term (7880). In contrast, in the first trimester, TLR2 and TLR4 proteins are expressed in VCT and EVT, but minimally in SCT (81, 82) (Figure 3). There is therefore variation in TLR2 and TLR4 expression in the different trophoblast lineages across pregnancy. Why and how such dynamic regulation of TLR expression occurs during gestation requires further investigation in a broader range of human placental samples (different donors, gestation stages, genetic background, sampling regions). It is likely that alteration in cytokines profiles in the microenvironment as pregnancy progresses (83) may result in the variation in the expression of TLRs in the placenta. Current evidence is only limited to in vitro TLR2/4 stimulation studies using placental explants and primary first trimester trophoblast cells, which drives the expression of

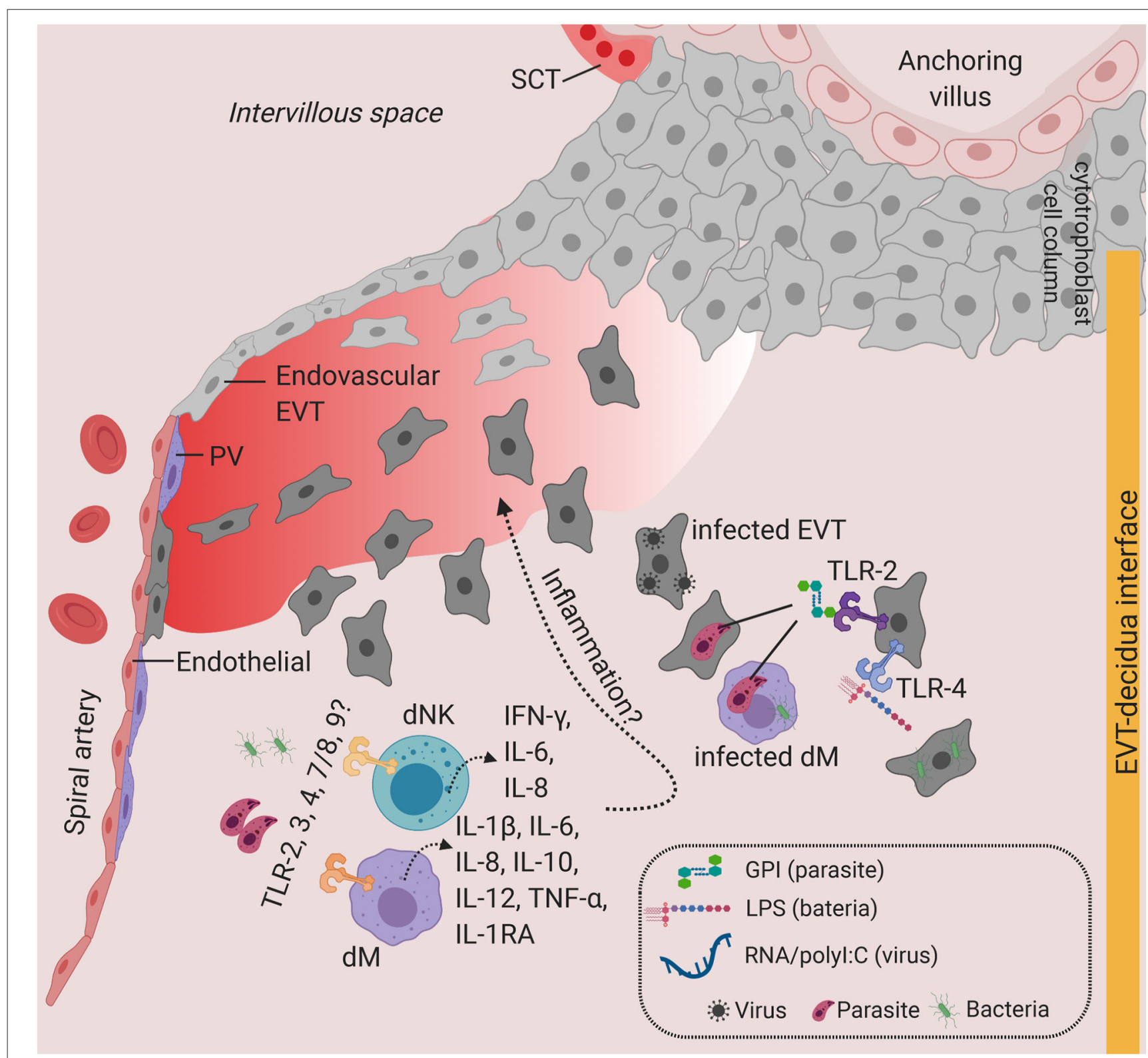

FIGURE 3 | Toll-like receptors and potential inflammatory response at the decidua. Predominant TLRs found in the human placenta from early and term pregnancies. TLR2 and TLR4 are expressed in EVT. dM and dNK also express a wide range of TLR families, where stimulation of TLR agonists lead to the production of a variety of cytokines and chemokines. Infiltration of infected cells and release of PAMPs in the decidua, which will activate TLR-mediated signaling. Overproduction of inflammatory cytokines at the decidua may lead to local inflammation. Figure is created by BioRender.com. 
pro-inflammatory cytokines IL-6, IL-8, TNF- $\alpha$, and IFN- $\gamma$ (78, 80, 81).

TLR2 and TLR4 proteins are expressed in HB cells, confirmed by co-expression of CD68 in healthy term placentas (78). In early pregnancy, our findings indicate that only TLR 4 but not TLR2 transcripts are expressed in steady-state HB cells (10) (Figure 4). Enhancement of IL-6 and IL-8 secretion upon stimulation of isolated first trimester HB cells with TLR4 agonist, LPS (84), does suggest a role for TLRs on HB cells in bacterial recognition and placental inflammation during early pregnancy. HB cells are postulated to have a role in viral replication $(41,42)$, however evidence on the expression and function of viral nucleic acid sensing receptors TLR3, TLR7, TLR8, and TLR9 in HB cells is lacking. Our findings show that TLR7, which recognizes viral single-strand RNA (ssRNA) (85) is expressed in steady-state HB cells (Figure 4) (10).

Other TLRs have also been shown to be expressed in decidua cells. $\mathrm{dMs}$ and $\mathrm{dNKs}$ isolated from first trimester pregnancies show steady state level expression of TLR1-9 transcripts and respond to a broad range of PAMPs, including heat-killed bacteria, microbial membranes, and nucleic acids (86). Stimulating primary dMs with these PAMPs produces high levels of TNF- $\alpha$, IL-1 $\beta$, IL-6, IL-8, IL-12, IL-10, and IL-1RA, whereas dNKs secrete IL-6, IL-8, and IFN- $\gamma$ (86). This study suggests that, in addition to the physiological roles of $\mathrm{dMs}$ and $\mathrm{dNKs}$ in accommodating the uterus for placentation, dMs and $\mathrm{dNKs}$ may play a role in pathogen recognition and antimicrobial response via activation of TLR signaling (Figure 3). The extent to which subsets of $\mathrm{dMs}$ or dNKs population (10) are critical for TLR-mediated response at the decidua is currently unknown.

In malaria endemic populations, single nucleotide polymorphisms (SNPs) within the TLR4 coding and TLR9 promoter regions are associated with variation in disease severity and parasitemia control $(87,88)$. In the case of pregnancy malaria, primiparous infected mothers with common TLR4 and TLR9 polymorphic variants are correlated with severe complications such as low birth weight and maternal anemia (89). This highlights the importance of studies involving large cohorts of individuals which include genotyping from pregnant mothers living in malaria endemic regions (see section on "Challenges and future perspective").

\section{TLRs in Animal Models of Placental Parasite Infection}

Animal models have also been used to study the functional role of TLR signaling, particularly for pathogens that are intracellular at some stage of their life cycle (Table 1). TLR4 and TLR9 are strongly activated by malaria parasite PAMPs such as glycosylphosphatidylinositol (GPI), DNA, and hemozoin $(90,91)$ (Figure 2). In a mouse model of placental malaria, TLR4, and Myd88 signaling activation resulted in placental expression of pro-inflammatory markers, such as IL-6 and TNF- $\alpha$ (92, 93). These studies also demonstrated that malaria parasite infection and inflammation in the mouse placenta lead to reduced fetus growth rate and disorganization of the vascular space in the placenta $(92,93)$. However, TLR-mediated inflammation and

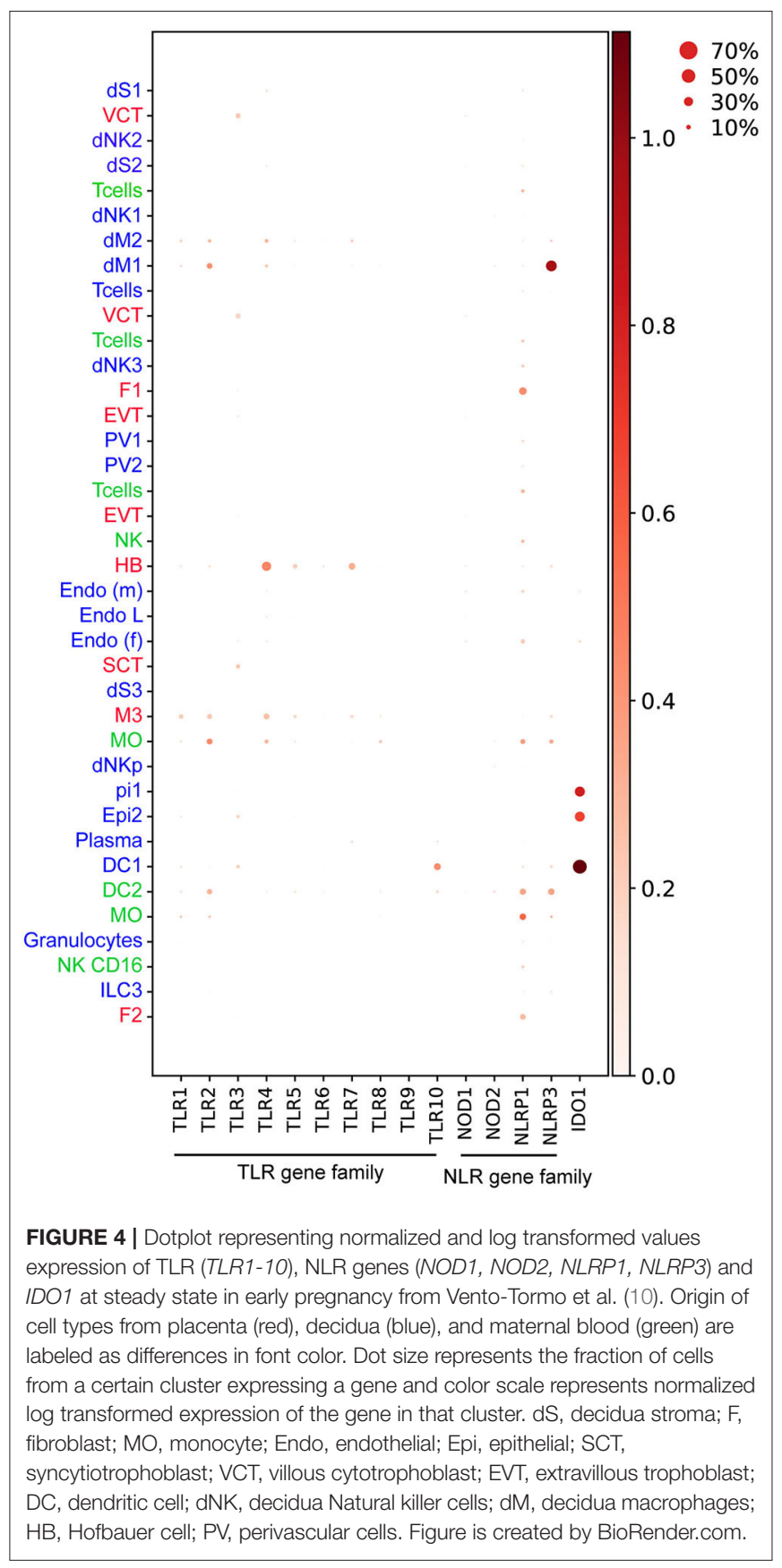

pathology in the human placenta upon malaria infection is unknown and remains to be further investigated.

Studies of congenital toxoplasmosis are also currently limited to animal models. TLR2 and TLR4 are associated with recognition of T. gondii's infection in mice (94). Engagement of the T. gondii ligand by TLR2 and TLR4 at the SCT-blood or in the EVT-decidua compartments is plausible, although there is still no direct evidence for such host-parasite interaction in humans. TLR11 has a role in controlling $T$. gondii infection in mice $(95,96)$, however in humans TLR11 is a pseudogene and is not expressed (97). 


\section{CYTOSOLIC PATTERN RECOGNITION RECEPTORS: RIG-I, MDA5, AND NOD-LIKE RECEPTORS AT THE UTERINE-PLACENTAL INTERFACE}

Cytosolic PRRs play an important role in fighting against viral infection by eliciting host type I interferons (IFN) antiviral response through recognition of single and double stranded RNA (ssRNA and dsRNA) $(98,99)$. Examples of PRRs are the cytosolic retinoic acid-inducible gene-I-like (RIG-I) and the melanoma differentiation-associated protein 5 (MDA5) receptors, both expressed in the SCT and VCT of term placenta (100). In the human placenta, there is limited information on the function of RIG-1 and MDA5, but they may play a crucial role in recognizing a variety of RNA viruses, including ZIKV and dengue virus (101).

The Nucleotide binding Oligomerization Domain-like receptors (NOD-like receptors; NLR) recognizes intracellular pathogen products which have entered into the host cytoplasmic compartment (74). Both NOD-1 and NOD-2 receptors, which are known to detect intracellular bacterial peptidoglycans (102), are expressed in the SCT in the first trimester and term placentas $(103,104)$. The NLR pyrin-containing 1 and 3 proteins (NLRP1 and NLRP3) form the major inflammasome complexes, which contribute to activation of inflammatory caspases and pathogen clearance $(105,106)$.

Activation of NLRP3 and AIM2 inflammasomes, together with high expression of IL-1R, IL- $1 \beta$, and caspase- 1 was recently shown in the placental tissue of mothers infected with $P$. falciparum with significant pathology (107). In a murine model of intra-amniotic inflammation induced by bacterial LPS, tissue sections from the decidua basalis region expressed high levels of NLRP3, but negligible caspase-1 activation suggesting a possible non-canonical activation of the NLRP3 inflammasome (108). Our analysis shows that decidual dM1 expresses high levels of NLRP3 transcript at steady state compared to other cell types (10) (Figure 4), thus dM1 may play a role in NLRP3-mediated pathogen recognition during early pregnancy.

\section{SECRETED HOST DEFENSES AT THE UTERINE-PLACENTAL INTERFACE}

\section{Antimicrobial Peptides}

AMP secreted by epithelial and immune cells are small peptides that bind and destroy most groups of pathogens-bacteria, yeasts, fungi, and viruses (109). In addition to direct killing of pathogens, AMPs can rapidly modulate innate host immune responses by recruiting myeloid cells and lymphocytes to the site of infection and mediating activation of TLR $(110,111)$. The human placenta expresses high levels of $\beta$-defensins, a family of broad spectrum antimicrobial peptides which participate in direct bactericidal and anti-viral activity (112). Specific subtypes of $\beta$-defensins (HBD-1, 2, and 3) are expressed in SCTs (112), suggesting these AMPs can target potentially bacterial or viral infection from the maternal blood.

\section{Antiviral Interferons}

Recognition of PAMPs by PRRs during infection leads to production of pro-inflammatory cytokines that can aid in clearing the pathogen (74). Studies on the direct role of proinflammatory cytokines on the placenta in the case of infection is limited. Inflammatory mediators can directly influence infection outcome and fetal development, but they can also cause damage to the placenta if produced in excess (113). Amongst the proinflammatory cytokines associated with uterine-placental infection during pregnancy, the antiviral IFN are the most well-characterized.

IFNs are secreted by a variety of cell types as the first line of defense against viral infection (114). Type I IFNs, including IFN- $\alpha$ and IFN- $\beta$, are potent antiviral cytokines. IFN- $\alpha$ and IFN- $\beta$ bind to the IFNAR $1 / 2$ receptor and lead to expression of IFN stimulated genes (ISGs), which control virus infection through a variety of mechanisms (114). Loss of IFNAR in the placenta leads to vertical transmission and fetal mortality in murine herpesvirus-68 (MHV68) infected mice (115). In the mouse model of ZIKV infection, type I IFN-mediated signaling is essential for the control of viral replication in the placenta, but can also lead to significant placental pathology and fetal mortality $(116,117)$. The mechanism of type I IFN-mediated placental pathology has been recently elucidated. IFN-induced transmembrane (IFITM) protein, which normally blocks viral entry into host cells, impairs syncytin-mediated fusion of VCT to form SCT, leading to aberrant placental development (118).

Type II IFN, IFN $\gamma$, predominantly produced by NK and CD4+ T cells is crucial in controlling parasitic infection, such as T. gondii in mice $(94,119)$. However, elevated levels of IFN $\gamma$ in response to T. gondii infection can lead to pathological effects during pregnancy including fetal demise $(119,120)$. Severe placental pathology and fetal death have also been associated with elevation of IFN $\gamma$ during pregnancy in a murine model of malaria (121). Hence, proper regulation of type I and II IFN-mediated signaling at the uterine-placental interface is crucial in limiting pathogen replication, whilst preserving a balanced environment for normal placental development (122). Type III IFN, IFN $\lambda$, are constitutively secreted by the human SCT, which presumably confers antiviral effects against ZIKV infection (123-125).

\section{INTRACELLULAR HOST DEFENSES AT THE UTERINE-PLACENTAL INTERFACE}

\section{Tryptophan Metabolism by IDO}

Indoleamine 2,3-dioxygenase (IDO) is a host intracellular enzyme which metabolizes the amino acid tryptophan (126). IDO has been associated with maternal immunoregulation during pregnancy (127). It also plays a key role in the control of bacterial and viral replication, through limiting the bioavailability of tryptophan (128). IDO also inhibits the replication of several parasitic pathogens including $T$. gondii in human fibroblasts (129) and Leishmania spp in human macrophages (130). Mouse infection with $L$. monocytogenes showed that IDO is elevated in an IFN- $\gamma$-dependent manner in stromal cells of the metrial gland and decidua basalis; a crucial process to resolve bacterial 
infection in the mouse placenta (131). Our findings also show IDO1 expression is enriched in epithelial glandular and DC1 cell type in the first trimester decidua (10) (Figure 4). The presence of IDO in decidua suggests that the enzyme might have a central role in limiting parasitic, viral, and bacterial replication, thus preventing their spread to the fetus.

\section{CHALLENGES AND FUTURE PERSPECTIVES}

Research on how the human placenta safeguards itself against infections is challenging due to obvious logistical and ethical issues in obtaining tissue from early in gestation (Box 1). Although animal experimental models have provided important insights relating to the immune responses to pathogenic infection, major differences between human and animal placentas must be considered $(30,31)$. Likewise, differences between strains of pathogens adapted for mice compared with human clinical isolates should be taken into account as this may lead to variation in pathogenesis and cellular response. One such example is the use of mouse CMV, which is unable to cross the mouse placental barrier, unlike the HMVC counterpart which can be transmitted transplacentally in humans (132). Therefore, all data obtained from studies of infection in pregnant animals needs careful interpretation and consideration prior to translation to clinical infection in humans.

Inherent properties of trophoblast cell lines, primary cultures or explants vary between donors, and are likely to be confounded by the area of the placenta that is sampled and as well as stage of gestation (133). For instance, villous placental explants will vary depending on the types of villi sampled and the presence of

BOX 1 | Perspective of vertical transmission and innate immune function during pregnancy and infection.

A variety of maternal infections can lead to vertical transmission (Table 1). The exact mechanisms these pathogens use to escape host defense and cross the placental barrier into the fetal compartment are not entirely known. Experimental models that recapitulate infection of the human placenta and thus vertical transmission are challenging to set up. More data and representative experimental models are needed to answer these questions: (i) how do different pathogens escape or modulate the maternal-fetal host innate immune barrier (ii) why do some pathogens lead to congenital infection but not others? Studying infected human placentas will be essential in understanding this but access to these samples is difficult especially in low and middle-income countries (LMIC) where maternal infection is particularly prevalent (WHO, Maternal mortality index 2019). Despite evidence of expression in primary placental tissue, functional studies on important innate immune features such as TLRs, AMPs, RIG-I, MDA5, NLRs, and IDO during infection and pregnancy are lacking. Understanding how different cell types at the uterine-placental interface ( $\mathrm{HB}$ cells, dNKs, and $\mathrm{dMs}$ ) respond to pathogen challenge is essential, but remains under-researched. A critical obstacle is to also extrapolate the protective and pathological mechanisms of cytokines from mouse to human infection. Therefore, systematic comparison of the innate immune effector mechanisms across gestation, in the placenta and decidua from natural human infection vs. healthy pregnancy, will provide a more accurate representation in clinical settings. attached decidual tissue (133). Caution is therefore needed when interpreting data using these experimental models.

To overcome such limitations, population-based cohort studies of women with infection during pregnancy with extensive tissue sampling should be performed. These need to include and focus on LMIC where infection is still a major cause of maternal and fetal mortality and morbidity. Cohort studies and epidemiological surveillance on maternal infections can offer significant insights into disease pathogenesis and accelerate clinical interventions (134). Collaborations between clinicians and researchers for population-based cohort collection and sample processing will be instrumental to achieving this goal. Biological samples such as blood or placenta collected from controls and infected pregnant individuals could be stored and cryopreserved retrospectively. To capture the overall heterogeneity of infected and non-infected placenta samples, sampling, and biobanking criteria of different regions of placenta should be considered (135). Protocols are now available to use frozen tissue processed for single-cell/nuclei and spatial genomics $(136,137)$. Hence, application of single-cell "omics" on infected vs. healthy human placental and decidual samples will enable us to evaluate cellular heterogeneity in response to infection.

The capacity to detect transcripts specific to host or pathogen mRNA from the same tissue using in situ nucleic acid hybridization methods will provide direct quantification of infection burden and identification of potential target host cells within the same tissue (138). Recent advances in spatial transcriptomics methods have also allowed gene expression signatures to be quantified and resolved from individual tissue sections (139). Combination of these emerging technologies with new methods to integrate single-cell and spatial data computationally (140) will provide an unbiased approach to characterize and profile the transcriptome of individual cells in situ from the placenta and decidua in response to infections. We anticipate that high-throughput datasets generated from cohort sampling studies will unravel novel cell states and tissue spatial localization associated with placental infections and inflammation. This will also allow us to better characterize not only the innate immune response or makers of infection, but also other adaptive immune states in the human placenta (Box 1).

The use of in vitro models will also further define host responses to infection. The recent generation of human trophoblast stem cells (hTSCs) (141) and three-dimensional (3D) trophoblast organoids $(142,143)$ offer a great opportunity to study infections in early pregnancy where the access to first trimester placental samples is a concern. More importantly, the hTSCs and trophoblast organoids fulfill the criteria characteristic of human first trimester trophoblast in vivo (32). Both hTSCs and trophoblast organoids can differentiate in vitro into SCT and EVT with appropriate media $(142,143)$ allowing infection experiments on both the major trophoblast subpopulations present at the two major sites of contact between maternal and fetal cells. Sequencing of both host and pathogen transcriptomes from infected trophoblast at single-cell resolution will also advance our understanding on host-pathogen interactions in placentas $(144,145)$. 
Further refinement of the trophoblast organoid and hTSCs culture system is needed to address key biological questions unanswered by current models. These include studying the effect of infection on cellular crosstalk between trophoblast and other primary placental cells such as $\mathrm{HB}$ cells, or decidual cells in culture, such as dNK or decidual stromal cells. Adaptation of CRISPR/Cas9 genome editing technology for the trophoblast organoids or hTSCs will offer novel insights into essential host genes required for vertical transmission and placental defense mechanisms in humans.

\section{CONCLUSION}

Major maternal and fetal complications as a result of infection are still a concern, especially in LMIC with highest prevalence reported in countries of sub-Saharan Africa (WHO, Maternal mortality index 2019). Profound limitations on current study models and ethical regulations on studying human placenta have significantly delayed the development of therapies and vaccines for maternal-fetal infection. How vertical transmission occurs and how the uterine-placental innate immune system reacts to infection remain as major unresolved questions. Revolutionary advances in single-cell genomics, imaging, computational, and stem cell biology methods are currently underway to study the molecular and cellular mechanisms of human diseases. Therefore, it is now an exciting time to apply these transformative technologies to comprehensively address

\section{REFERENCES}

1. Benirschke K, Kaufmann P, Baergen RN. Pathology of the Human Placenta. Berlin; Heidelberg: Springer (2006).

2. Schlafke S, Enders AC. Cellular basis of interaction between trophoblast and uterus at implantation. Biol Reprod. (1975) 12:41-65. doi: 10.1095/biolreprod12.1.41

3. PrabhuDas M, Bonney E, Caron K, Dey S, Erlebacher A, Fazleabas A, et al. Immune mechanisms at the maternal-fetal interface: perspectives and challenges. Nat Immunol. (2015) 16:328-34. doi: 10.1038/ni.3131

4. Ander SE, Diamond MS, Coyne CB. Immune responses at the maternal-fetal interface. Sci Immunol. (2019) 4:eaat6114. doi: 10.1126/sciimmunol.aat6114

5. Coyne CB, Lazear HM. Zika virus - reigniting the TORCH. Nat Rev Microbiol. (2016) 14:707-15. doi: 10.1038/nrmicro.2016.125

6. Yarbrough VL, Winkle S, Herbst-Kralovetz MM. Antimicrobial peptides in the female reproductive tract: a critical component of the mucosal immune barrier with physiological and clinical implications. Hum Reprod Update. (2015) 21:353-77. doi: 10.1093/humupd/dmu065

7. Romero R, Gomez-Lopez N, Winters AD, Jung E, Shaman M, Bieda J, et al. Evidence that intra-amniotic infections are often the result of an ascending invasion - a molecular microbiological study. J Perinat Med. (2019) 47:91531. doi: 10.1515/jpm-2019-0297

8. Kim CJ, Romero R, Chaemsaithong P, Chaiyasit N, Yoon BH, Kim YM. Acute chorioamnionitis and funisitis: definition, pathologic features, and clinical significance. Am J Obstet Gynecol. (2015) 213:S29-52. doi: 10.1016/j.ajog.2015.08.040

9. Cappelletti M, Presicce P, Kallapur SG. Immunobiology of acute chorioamnionitis. Front Immunol. (2020) 11:649. doi: 10.3389/fimmu.2020.00649 fundamental questions on host-pathogen interaction at the human uterine-placental interface.

\section{AUTHOR CONTRIBUTIONS}

$\mathrm{RH}, \mathrm{AN}$, and RV-T wrote and edited the manuscript. All authors contributed to the article and approved the submitted version.

\section{FUNDING}

$\mathrm{RH}$ and RV-T were supported by Wellcome Sanger core funding (WT206194). AN was supported by a Sanger International fellowship, a NURTURE fellowship (D43TW010132) and a group leader award supported through the DELTAS Africa Initiative $(107743 / \mathrm{Z} / 15 / \mathrm{Z})$. The DELTAS Africa Initiative is an independent funding scheme of the African Academy of Science (AAS), Alliance for Accelerating Excellence in Science in Africa (AESA), supported by the New Partnership for Africa's Development Planning and Coordinating Agency (NEPAD Agency) with funding from the Wellcome Trust (grant no. 107743), and the UK government.

\section{ACKNOWLEDGMENTS}

We would like to thank Ashely Moffett for the useful discussions and critical review of the manuscript. We are also very grateful to Sarah Aldridge, Loren Gibson, Damiana Alvarez, Carlos Talavera-Lopez, and Anna Arutyunyan for their insightful comments and corrections.
10. Vento-Tormo R, Efremova M, Botting RA, Turco MY, VentoTormo M, Meyer KB, et al. Single-cell reconstruction of the early maternal-fetal interface in humans. Nature. (2018) 563:347-53. doi: 10.1038/s41586-018-0698-6

11. McDonagh S, Maidji E, Ma W, Chang H-T, Fisher S, Pereira L. Viral and bacterial pathogens at the maternal-fetal interface. J Infect Dis. (2004) 190:826-34. doi: 10.1086/422330

12. Vornhagen J, Adams Waldorf KM, Rajagopal L. Perinatal Group B streptococcal infections: virulence factors, immunity, and prevention strategies. Trends Microbiol. (2017) 25:91931. doi: 10.1016/j.tim.2017.05.013

13. Hamon M, Bierne H, Cossart P. Listeria monocytogenes: a multifaceted model. Nat Rev Microbiol. (2006) 4:423-34. doi: 10.1038/nrmicro1413

14. Stein A, Raoult D. Q fever during pregnancy: a public health problem in southern France. Clin Infect Dis. (1998) 27:592-6. doi: 10.1086/514698

15. Thomas DD, Navab M, Haake DA, Fogelman AM, Miller JN, Lovett MA. Treponema pallidum invades intercellular junctions of endothelial cell monolayers. Proc Natl Acad Sci USA. (1988) 85:3608-12. doi: 10.1073/pnas.85.10.3608

16. Peeling RW, Mabey DCW. Syphilis. Nat Rev Microbiol. (2004) 2:4489. doi: $10.1038 /$ nrmicro914

17. Montoya JG, Liesenfeld O. Toxoplasmosis. Lancet. (2004) 363:196576. doi: 10.1016/S0140-6736(04)16412-X

18. Kemmerling U, Osuna A, Schijman AG, Truyens C. Congenital transmission of trypanosoma cruzi: a review about the interactions between the parasite, the placenta, the maternal and the fetal/neonatal immune responses. Front Microbiol. (2019) 10:1854. doi: 10.3389/fmicb.2019.01854

19. Maidji E, McDonagh S, Genbacev O, Tabata T, Pereira L. Maternal antibodies enhance or prevent cytomegalovirus infection in the placenta by 
neonatal Fc receptor-mediated transcytosis. Am J Pathol. (2006) 168:121026. doi: 10.2353/ajpath.2006.050482

20. Lazar M, Perelygina L, Martines R, Greer P, Paddock CD, Peltecu G, et al. Immunolocalization and distribution of rubella antigen in fatal congenital rubella syndrome. EBioMedicine. (2016) 3:86-92. doi: 10.1016/j.ebiom.2015.11.050

21. Ganaie SS, Qiu J. Recent advances in replication and infection of human parvovirus B19. Front Cell Infect Microbiol. (2018) 8:166. doi: $10.3389 /$ fcimb. 2018.00166

22. Enders G, Miller E, Cradock-Watson J, Bolley I, Ridehalgh M. Consequences of varicella and herpes zoster in pregnancy: prospective study of 1739 cases. Lancet. (1994) 343:1548-51. doi: 10.1016/S0140-6736(94)92943-2

23. El Costa H, Gouilly J, Mansuy J-M, Chen Q, Levy C, Cartron G, et al. ZIKA virus reveals broad tissue and cell tropism during the first trimester of pregnancy. Sci Rep. (2016) 6:35296. doi: 10.1038/srep35296

24. Foo S-S, Chen W, Chan Y, Bowman JW, Chang L-C, Choi Y, et al, Asian Zika virus strains target CD14+ blood monocytes and induce M2-skewed immunosuppression during pregnancy. Nat Microbiol. (2017) 2:1558-70. doi: 10.1038/s41564-017-0016-3

25. Michlmayr D, Andrade P, Gonzalez K, Balmaseda A, Harris E. $\mathrm{CD} 14+\mathrm{CD} 16+$ monocytes are the main target of Zika virus infection in peripheral blood mononuclear cells in a paediatric study in Nicaragua. Nat Microbiol. (2017) 2:1462-70. doi: 10.1038/s41564-017-0035-0

26. Delorme-Axford E, Sadovsky Y, Coyne CB. The placenta as a barrier to viral infections. Annu Rev Virol. (2014) 1:13346. doi: 10.1146/annurev-virology-031413-085524

27. Pereira L. Congenital viral infection: traversing the uterine-placental interface. Annu Rev Virol. (2018) 5:27399. doi: 10.1146/annurev-virology-092917-043236

28. Lecuit M. Understanding how listeria monocytogenes targets and crosses host barriers. Clin Microbiol Infect. (2005) 11:4306. doi: 10.1111/j.1469-0691.2005.01146.x

29. Persson CM, Lambert H, Vutova PP, Dellacasa-Lindberg I, Nederby J, Yagita $\mathrm{H}$, et al. Transmission of Toxoplasma gondii from infected dendritic cells to natural killer cells. Infect Immun. (2009) 77:970-6. doi: 10.1128/IAI.00833-08

30. Turco MY, Moffett A. Development of the human placenta. Development. (2019) 146:3613. doi: 10.1242/dev.163428

31. Carter AM. Animal models of human placentation - a review. Placenta. (2007) 28:S41-7. doi: 10.1016/j.placenta.2006.11.002

32. Lee CQE, Gardner L, Turco M, Zhao N, Murray MJ, Coleman $\mathrm{N}$, et al. What is trophoblast? A combination of criteria define human first-trimester trophoblast. Stem Cell Rep. (2016) 6:257-72. doi: 10.1016/j.stemcr.2016.01.006

33. Hemberger M, Udayashankar R, Tesar P, Moore H, Burton GJ. ELF5enforced transcriptional networks define an epigenetically regulated trophoblast stem cell compartment in the human placenta. Hum Mol Genet. (2010) 19:2456-67. doi: 10.1093/hmg/ddq128

34. Boyd JD, Hamilton WJ. The Human Placenta. London: Macmillan Press (1975).

35. Pijnenborg R, Bland JM, Robertson WB, Brosens I. Uteroplacental arterial changes related to interstitial trophoblast migration in early human pregnancy. Placenta. (1983) 4:397-413. doi: 10.1016/S0143-4004(83)80043-5

36. Pijnenborg R. Trophoblast invasion. Reprod Med Rev. (1994) 3:5373. doi: $10.1017 /$ S0962279900000776

37. Burton GJ, Jauniaux E, Watson AL. Maternal arterial connections to the placental intervillous space during the first trimester of human pregnancy: the Boyd collection revisited. Am J Obstet Gynecol. (1999) 181:71824. doi: 10.1016/S0002-9378(99)70518-1

38. Enders AC, King BF. The cytology of Hofbauer cells. Anat Rec. (1970) 167:231-6. doi: 10.1002/ar.1091670211

39. Castellucci M, Zaccheo D, Pescetto G. A three-dimensional study of the normal human placental villous core. Cell Tissue Res. (1980) 210:23547. doi: $10.1007 / \mathrm{BF} 00237612$

40. Wetzka B, Clark DE, Charnock-Jones DS, Zahradnik HP, Smith SK. Isolation of macrophages (Hofbauer cells) from human term placenta and their prostaglandin E2 and thromboxane production. Hum Reprod. (1997) 12:847-52. doi: 10.1093/humrep/12.4.847
41. de Noronha L, Zanluca C, Burger M, Suzukawa AA, Azevedo M, Rebutini PZ, et al. Zika virus infection at different pregnancy stages: anatomopathological findings, target cells and viral persistence in placental tissues. Front Microbiol. (2018) 9:2266. doi: 10.3389/fmicb.2018.02266

42. Bhatnagar J, Rabeneck DB, Martines RB, Reagan-Steiner S, Ermias Y, Estetter LBC, et al. Zika virus RNA replication and persistence in brain and placental tissue. Emerg Infect Dis. (2017) 23:405-14. doi: 10.3201/eid2303.161499

43. Lewis SH, Reynolds-Kohler C, Fox HE, Nelson JA. HIV-1 in trophoblastic and villous Hofbauer cells, and haematological precursors in eight-week fetuses. Lancet. (1990) 335:565-8. doi: 10.1016/0140-6736(90)90349-A

44. Quicke KM, Bowen JR, Johnson EL, McDonald CE, Ma H, O'Neal JT, et al. Zika virus infects human placental macrophages. Cell Host Microbe. (2016) 20:83-90. doi: 10.1016/j.chom.2016.05.015

45. Hunt JS, Pollard JW. Macrophages in the uterus and placenta. Curr Top Microbiol Immunol. (1992) 181:39-63. doi: 10.1007/978-3-642-77377-8_2

46. Zeldovich VB, Clausen CH, Bradford E, Fletcher DA, Maltepe E, Robbins JR, et al. Placental syncytium forms a biophysical barrier against pathogen invasion. PLoS Pathogens. (2013) 9:e1003821. doi: 10.1371/journal.ppat.1003821

47. Nelson DM. Apoptotic changes occur in syncytiotrophoblast of human placental villi where fibrin type fibrinoid is deposited at discontinuities in the villous trophoblast. Placenta. (1996) 17:387-91. doi: 10.1016/S0143-4004(96)90019-3

48. Tabata T, Petitt M, Puerta-Guardo H, Michlmayr D, Wang C, Fang-Hoover $\mathrm{J}$, et al. Zika virus targets different primary human placental cells, suggesting two routes for vertical transmission. Cell Host Microbe. (2016) 20:15566. doi: $10.1016 /$ j.chom.2016.07.002

49. Maidji E, Genbacev O, Chang H-T, Pereira L. Developmental regulation of human cytomegalovirus receptors in cytotrophoblasts correlates with distinct replication sites in the placenta. J Virol. (2007) 81:470112. doi: $10.1128 /$ JVI.02748-06

50. Pique-Regi R, Romero R, Tarca AL, Luca F, Xu Y, Alazizi A, et al. Does the human placenta express the canonical cell entry mediators for SARS-CoV-2? Elife. (2020) 9:e58716. doi: 10.7554/eLife.58716

51. Pique-Regi R, Romero R, Tarca AL, Sendler ED, Xu Y, Garcia-Flores $\mathrm{V}$, et al. Single cell transcriptional signatures of the human placenta in term and preterm parturition. Elife. (2019) 8:e52004. doi: 10.7554/eLif e.52004

52. Sungnak W, Huang N, Bécavin C, Berg M, Queen R, Litvinukova $\mathrm{M}$, et al. SARS-CoV-2 entry factors are highly expressed in nasal epithelial cells together with innate immune genes. Nat Med. (2020) 6817. doi: 10.1038/s41591-020-0868-6

53. Algarroba GN, Rekawek P, Vahanian SA, Khullar P, Palaia T, Peltier $\mathrm{MR}$, et al. Visualization of SARS-CoV-2 virus invading the human placenta using electron microscopy. Am J Obstet Gynecol. (2020) 223:27527. doi: $10.1016 /$ j.ajog.2020.05.023

54. Hosier H, Farhadian SF, Morotti RA, Deshmukh U, Lu-Culligan A, Campbell KH, et al. SARS-CoV-2 infection of the placenta. J Clin Invest. (2020). doi: 10.1172/JCI139569. [Epub ahead of print].

55. Kirtsman M, Diambomba Y, Poutanen SM, Malinowski AK, Vlachodimitropoulou E, Parks WT, et al. Probable congenital SARS$\mathrm{CoV}-2$ infection in a neonate born to a woman with active SARS-CoV-2 infection. CMAJ. (2020) 192:E647-50. doi: 10.1503/cmaj.200821

56. Simister NE, Story CM, Chen HL, Hunt JS. An IgG-transporting Fc receptor expressed in the syncytiotrophoblast of human placenta. Eur J Immunol. (1996) 26:1527-31. doi: 10.1002/eji.1830260718

57. Rathore APS, Saron WAA, Lim T, Jahan N, St. John AL. Maternal immunity and antibodies to dengue virus promote infection and Zika virus-induced microcephaly in fetuses. Sci Adv. (2019) 5:eaav3208. doi: 10.1126/sciadv.aav3208

58. Gupta S, Gach JS, Becerra JC, Phan TB, Pudney J, Moldoveanu Z, et al. The Neonatal Fc receptor ( $F c R n$ ) enhances human immunodeficiency virus type 1 (HIV-1) transcytosis across epithelial cells. PLoS Pathog. (2013) 9:e1003776. doi: 10.1371/journal.ppat.1003776

59. Georgieff MK, Wobken JK, Welle J, Burdo JR, Connor JR. Identification and localization of divalent metal transporter-1 (DMT-1) in term human placenta. Placenta. (2000) 21:799-804. doi: 10.1053/plac.2000.0566 
60. Martin DN, Uprichard SL. Identification of transferrin receptor 1 as a hepatitis C virus entry factor. Proc Natl Acad Sci USA. (2013) 110:10777782. doi: 10.1073/pnas.1301764110

61. Drakesmith H, Prentice A. Viral infection and iron metabolism. Nat Rev Microbiol. (2008) 6:541-52. doi: 10.1038/nrmicro1930

62. Rogerson SJ, Hviid L, Duffy PE, Leke RFG, Taylor DW. Malaria in pregnancy: pathogenesis and immunity. Lancet Infect Dis. (2007) 7:10517. doi: 10.1016/S1473-3099(07)70022-1

63. Fried M, Duffy PE. Adherence of Plasmodium falciparum to chondroitin sulfate A in the human placenta. Science. (1996) 272:1502-4. doi: $10.1126 /$ science.272.5267.1502

64. Crocker IP, Tanner OM, Myers JE, Bulmer JN, Walraven G, Baker PN. Syncytiotrophoblast degradation and the pathophysiology of the malaria-infected placenta. Placenta. (2004) 25:27382. doi: 10.1016/j.placenta.2003.09.010

65. Pereira L, Maidji E, McDonagh S, Genbacev O, Fisher S. Human cytomegalovirus transmission from the uterus to the placenta correlates with the presence of pathogenic bacteria and maternal immunity. J Virol. (2003) 77:13301-14. doi: 10.1128/JVI.77.24.13301-13314.2003

66. Fowler KB, Stagno S, Pass RF. Interval between births and risk of congenital cytomegalovirus infection. Clin Infect Dis. (2004) 38:10357. doi: $10.1086 / 382533$

67. Fowler KB, Stagno S, Pass RF. Maternal immunity and prevention of congenital cytomegalovirus infection. JAMA. (2003) 289:1008-11. doi: 10.1001/jama.289.8.1008

68. Parruti G, Polilli E, Ursini T, Tontodonati M. Properties and mechanisms of immunoglobulins for congenital cytomegalovirus disease. Clin Infect Dis. (2013) 57(Suppl. 4):S185-8. doi: 10.1093/cid/cit584

69. Siewiera J, El Costa H, Tabiasco J, Berrebi A, Cartron G, Le Bouteiller $\mathrm{P}$, et al. Human cytomegalovirus infection elicits new decidual natural killer cell effector functions. PLoS Pathog. (2013) 9:e1003257. doi: 10.1371/journal.ppat.1003257

70. Crespo ÂC, Strominger JL, Tilburgs T. Expression of KIR2DS1 by decidual natural killer cells increases their ability to control placental HCMV infection. Proc Natl Acad Sci USA. (2016) 113:15072-7. doi: 10.1073/pnas.1617927114

71. van der Ploeg K, Chang C, Ivarsson MA, Moffett A, Wills MR, Trowsdale J. Modulation of human leukocyte Antigen-C by human cytomegalovirus stimulates KIR2DS1 recognition by natural killer cells. Front Immunol. (2017) 8:298. doi: 10.3389/fimmu.2017.00298

72. Quillay H, El Costa H, Duriez M, Marlin R, Cannou C, Madec Y, et al. NK cells control HIV-1 infection of macrophages through soluble factors and cellular contacts in the human decidua. Retrovirology. (2016) 13:39. doi: $10.1186 / \mathrm{s} 12977-016-0271-\mathrm{z}$

73. Janeway CA Jr, Medzhitov R. Innate immune recognition. Annu Rev Immunol. (2002) 20:197216. doi: 10.1146/annurev.immunol.20.083001.084359

74. Akira S, Uematsu S, Takeuchi O. Pathogen recognition and innate immunity. Cell. (2006) 124:783-801. doi: 10.1016/j.cell.2006.02.015

75. Banchereau J, Steinman RM. Dendritic cells and the control of immunity. Nature. (1998) 392:245-52. doi: 10.1038/32588

76. Kawasaki T, Kawai T. Toll-like receptor signaling pathways. Front Immunol. (2014) 5:461. doi: 10.3389/fimmu.2014.00461

77. Honda K, Taniguchi T. IRFs: master regulators of signalling by Toll-like receptors and cytosolic pattern-recognition receptors. Nat Rev Immunol. (2006) 6:644-58. doi: 10.1038/nri1900

78. Ma Y, Krikun G, Abrahams VM, Mor G, Guller S. Cell type-specific expression and function of toll-like receptors 2 and 4 in human placenta: implications in fetal infection. Placenta. (2007) 28:102431. doi: 10.1016/j.placenta.2007.05.003

79. Beijar ECE, Mallard C, Powell TL. Expression and subcellular localization of TLR-4 in term and first trimester human placenta. Placenta. (2006) 27:322-6. doi: 10.1016/j.placenta.2004.12.012

80. Holmlund U, Cebers G, Dahlfors AR, Sandstedt B, Bremme K, Ekström ES, et al. Expression and regulation of the pattern recognition receptors Toll-like receptor-2 and Toll-like receptor-4 in the human placenta. Immunology. (2002) 107:145-51. doi: 10.1046/j.1365-2567.2002. 01491.x
81. Abrahams VM, Bole-Aldo P, Kim YM, Straszewski-Chavez SL, Chaiworapongsa $\mathrm{T}$, Romero $\mathrm{R}$, et al. Divergent trophoblast responses to bacterial products mediated by TLRs. J Immunol. (2004) 173:4286-96. doi: 10.4049/jimmunol.173.7.4286

82. Pudney J, He X, Masheeb Z, Kindelberger DW, Kuohung W, Ingalls RR. Differential expression of toll-like receptors in the human placenta across early gestation. Placenta. (2016) 46:1-10. doi: 10.1016/j.placenta.2016.07.005

83. Koga K, Aldo PB, Mor G. Toll-like receptors and pregnancy: trophoblast as modulators of the immune response. J Obstet Gynaecol Res. (2009) 35:191-202. doi: 10.1111/j.1447-0756.2008.00963.x

84. Young OM, Tang Z, Niven-Fairchild T, Tadesse S, Krikun G, Norwitz ER et al. Toll-like receptor-mediated responses by placental Hofbauer Cells (HBCs): a potential pro-inflammatory role for Fetal M2 macrophages. Am J Reprod Immunol. (2015) 73:22-35. doi: 10.1111/aji.12336

85. Gantier MP, Tong S, Behlke MA, Xu D, Phipps S, Foster PS, et al. TLR7 is involved in sequence-specific sensing of singlestranded RNAs in human macrophages. J Immunol. (2008) 180:2117-24. doi: 10.4049/jimmunol.180.4.2117

86. Duriez M, Quillay H, Madec Y, El Costa H, Cannou C, Marlin R, et al. Human decidual macrophages and NK cells differentially express Toll-like receptors and display distinct cytokine profiles upon TLR stimulation. Front Microbiol. (2014) 5:316. doi: 10.3389/fmicb.2014.00316

87. Leoratti FMS, Farias L, Alves FP, Suarez-Mútis MC, Coura JR, Kalil J, et al. Variants in the toll-like receptor signaling pathway and clinical outcomes of malaria. J Infect Dis. (2008) 198:772-80. doi: 10.1086/590440

88. Mockenhaupt FP, Cramer JP, Hamann L, Stegemann MS, Eckert J, Oh N-R, et al. Toll-like receptor (TLR) polymorphisms in African children: common TLR-4 variants predispose to severe malaria. Proc Natl Acad Sci USA. (2006) 103:177-82. doi: 10.1073/pnas.0506803102

89. Mockenhaupt FP, Hamann L, von Gaertner C, Bedu-Addo G, von Kleinsorgen C, Schumann RR, et al. Common polymorphisms of toll-like receptors 4 and 9 are associated with the clinical manifestation of malaria during pregnancy. J Infect Dis. (2006) 194:184-8. doi: 10.1086/505152

90. Coban C, Ishii KJ, Kawai T, Hemmi H, Sato S, Uematsu S, et al. Tolllike receptor 9 mediates innate immune activation by the malaria pigment hemozoin. J Exp Med. (2005) 201:19-25. doi: 10.1084/jem.20041836

91. Krishnegowda G, Hajjar AM, Zhu J, Douglass EJ, Uematsu S, Akira S, et al. Induction of proinflammatory responses in macrophages by the glycosylphosphatidylinositols ofplasmodium falciparum. J Biol Chem. (2005) 280:8606-16. doi: 10.1074/jbc.m413541200

92. Barboza R, Reis AS, da Silva LG, Hasenkamp L, Pereira KRB, Câmara NOS, et al. MyD88 signaling is directly involved in the development of murine placental malaria. Infect Immun. (2014) 82:830-8. doi: 10.1128/IAI.01288-13

93. Barboza R, Lima FA, Reis AS, Murillo OJ, Peixoto EPM, Bandeira CL, et al. TLR4-mediated placental pathology and pregnancy outcome in experimental malaria. Sci Rep. (2017) 7:8623. doi: 10.1038/s41598-017-08299-x

94. Yarovinsky F. Innate immunity to Toxoplasma gondii infection. Nat Rev Immunol. (2014) 14:109-21. doi: 10.1038/nri3598

95. Yarovinsky F, Zhang D, Andersen JF, Bannenberg GL, Serhan CN, Hayden MS, et al. TLR11 activation of dendritic cells by a protozoan profilin-like protein. Science. (2005) 308:1626-9. doi: 10.1126/science.1109893

96. Plattner F, Yarovinsky F, Romero S, Didry D, Carlier M-F, Sher A, et al. Toxoplasma profilin is essential for host cell invasion and TLR11-dependent induction of an interleukin-12 response. Cell Host Microbe. (2008) 3:7787. doi: 10.1016/j.chom.2008.01.001

97. Zhang D, Zhang G, Hayden MS, Greenblatt MB, Bussey C, Flavell RA, et al. A toll-like receptor that prevents infection by uropathogenic bacteria. Science. (2004) 303:1522-6. doi: 10.1126/science.1094351

98. Yoneyama M, Onomoto K, Jogi M, Akaboshi T, Fujita T. Viral RNA detection by RIG-I-like receptors. Curr Opin Immunol. (2015) 32:4853. doi: 10.1016/j.coi.2014.12.012

99. Kato H, Takeuchi O, Mikamo-Satoh E, Hirai R, Kawai T, Matsushita K, et al. Length-dependent recognition of double-stranded ribonucleic acids by retinoic acid-inducible gene-I and melanoma differentiation-associated gene 5. J Exp Med. (2008) 205:1601-10. doi: 10.1084/jem.20080091

100. Bryant AH, Menzies GE, Scott LM, Spencer-Harty S, Davies LB, Smith $\mathrm{RA}$, et al. Human gestation-associated tissues express functional cytosolic 
nucleic acid sensing pattern recognition receptors. Clin Exp Immunol. (2017) 189:36-46. doi: 10.1111/cei.12960

101. Chazal M, Beauclair G, Gracias S, Najburg V, Simon-Lorière E, Tangy F, et al. RIG-I recognizes the $5^{\prime}$ region of Dengue and Zika virus genomes. Cell Rep. (2018) 24:320-8. doi: 10.1016/j.celrep.2018.06.047

102. Girardin SE, Boneca IG, Carneiro LAM, Antignac A, Jéhanno M, Viala J, et al. Nod1 detects a unique muropeptide from gram-negative bacterial peptidoglycan. Science. (2003) 300:1584-7. doi: 10.1126/science.1084677

103. Bryant AH, Bevan RJ, Spencer-Harty S, Scott LM, Jones RH, Thornton CA. Expression and function of NOD-like receptors by human term gestation-associated tissues. Placenta. (2017) 58:25-32. doi: 10.1016/j.placenta.2017.07.017

104. Costello MJ, Joyce SK, Abrahams VM. NOD protein expression and function in first trimester trophoblast cells. Am J Reprod Immunol. (2007) 57:6780. doi: 10.1111/j.1600-0897.2006.00447.x

105. Martinon F, Burns K, Tschopp J. The inflammasome: a molecular platform triggering activation of inflammatory caspases and processing of proIL-beta. Mol Cell. (2002) 10:417-26. doi: 10.1016/S1097-2765(02)00599-3

106. Franchi L, Muñoz-Planillo R, Núñez G. Sensing and reacting to microbes through the inflammasomes. Nat Immunol. (2012) 13:32532. doi: $10.1038 /$ ni.2231

107. Reis AS, Barboza R, Murillo O, Barateiro A, Peixoto EPM, Lima $\mathrm{FA}$, et al. Inflammasome activation and IL-1 signaling during placental malaria induce poor pregnancy outcomes. Sci Adv. (2020) 6:eaax6346. doi: 10.1126/sciadv.aax6346

108. Faro J, Romero R, Schwenkel G, Garcia-Flores V, Arenas-Hernandez $\mathrm{M}$, Leng $\mathrm{Y}$, et al. Intra-amniotic inflammation induces preterm birth by activating the NLRP3 inflammasome ${ }^{\dagger}$. Biol Reprod. (2019) 100:1290305. doi: 10.1093/biolre/ioy261

109. Hancock RE, Diamond G. The role of cationic antimicrobial peptides in innate host defences. Trends Microbiol. (2000) 8:402-10. doi: 10.1016/S0966-842X(00)01823-0

110. Yang D, Chertov O, Bykovskaia SN, Chen Q, Buffo MJ, Shogan J, et al. Betadefensins: linking innate and adaptive immunity through dendritic and $\mathrm{T}$ cell CCR6. Science. (1999) 286:525-8. doi: 10.1126/science.286.5439.525

111. Lande R, Gregorio J, Facchinetti V, Chatterjee B, Wang Y-H, Homey B, et al. Plasmacytoid dendritic cells sense self-DNA coupled with antimicrobial peptide. Nature. (2007) 449:564-9. doi: 10.1038/nature06116

112. King AE, Paltoo A, Kelly RW, Sallenave J-M, Bocking AD, Challis JRG. Expression of natural antimicrobials by human placenta and fetal membranes. Placenta. (2007) 28:161-9. doi: 10.1016/j.placenta.2006.01.006

113. Yockey LJ, Iwasaki A. Interferons and proinflammatory cytokines in pregnancy and fetal development. Immunity. (2018) 49:397-412. doi: 10.1016/j.immuni.2018.07.017

114. Sadler AJ, Williams BRG. Interferon-inducible antiviral effectors. Nat Rev Immunol. (2008) 8:559-68. doi: 10.1038/nri2314

115. Racicot K, Aldo P, El-Guindy A, Kwon J-Y, Romero R, Mor G. Cutting edge: fetal/placental Type I IFN can affect maternal survival and fetal viral load during viral infection. J Immunol. (2017) 198:302932. doi: $10.4049 /$ jimmunol.1601824

116. Yockey LJ, Jurado KA, Arora N, Millet A, Rakib T, Milano KM, et al. Type I interferons instigate fetal demise after Zika virus infection. Sci Immunol. (2018) 3:eaao1680. doi: 10.1126/sciimmunol.aao1680

117. Miner JJ, Cao B, Govero J, Smith AM, Fernandez E, Cabrera OH, et al. Zika virus infection during pregnancy in mice causes placental damage and fetal demise. Cell. (2016) 165:1081-91. doi: 10.1016/j.cell.2016.05.008

118. Buchrieser J, Degrelle SA, Couderc T, Nevers Q, Disson O, Manet C, et al. IFITM proteins inhibit placental syncytiotrophoblast formation and promote fetal demise. Science. (2019) 365:17680. doi: $10.1126 /$ science.aaw7733

119. Suzuki Y, Orellana MA, Schreiber RD, Remington JS. Interferon-gamma: the major mediator of resistance against Toxoplasma gondii. Science. (1988) 240:516-8. doi: 10.1126/science.3128869

120. Senegas A, Villard O, Neuville A, Marcellin L, Pfaff AW, Steinmetz T, et al. Toxoplasma gondii-induced foetal resorption in mice involves interferongamma-induced apoptosis and spiral artery dilation at the maternofoetal interface. Int J Parasitol. (2009) 39:481-7. doi: 10.1016/j.jpara.2008. 08.009
121. Niikura M, Inoue S-I, Mineo S, Asahi H, Kobayashi F. IFNGR1 signaling is associated with adverse pregnancy outcomes during infection with malaria parasites. PLOS ONE. (2017) 12:e0185392. doi: 10.1371/journal.pone.0185392

122. Yockey LJ, Lucas C, Iwasaki A. Contributions of maternal and fetal antiviral immunity in congenital disease. Science. (2020) 368:608-12. doi: 10.1126/science.aaz1960

123. Corry J, Arora N, Good CA, Sadovsky Y, Coyne CB. Organotypic models of type III interferon-mediated protection from Zika virus infections at the maternal-fetal interface. Proc Natl Acad Sci USA. (2017) 114:94338. doi: 10.1073/pnas.1707513114

124. Bayer A, Lennemann NJ, Ouyang Y, Bramley JC, Morosky S, Marques ETDA Jr, et al. Type III interferons produced by human placental trophoblasts confer protection against Zika virus infection. Cell Host Microbe. (2016) 19:705-12. doi: 10.1016/j.chom.2016.03.008

125. Jagger BW, Miner JJ, Cao B, Arora N, Smith AM, Kovacs A, et al. Gestational stage and IFN- $\lambda$ signaling regulate ZIKV infection in utero. Cell Host Microbe. (2017) 22:366-76.e3. doi: 10.1016/j.chom.2017.08.012

126. Munn DH, Mellor AL. Indoleamine 2,3 dioxygenase and metabolic control of immune responses. Trends Immunol. (2013) 34:137-43. doi: 10.1016/j.it.2012.10.001

127. Munn DH, Zhou M, Attwood JT, Bondarev I, Conway SJ, Marshall B, et al. Prevention of allogeneic fetal rejection by tryptophan catabolism. Science. (1998) 281:1191-3. doi: 10.1126/science.281.5380.1191

128. Schmidt SV, Schultze JL. New insights into IDO biology in bacterial and viral infections. Front Immunol. (2014) 5:384. doi: 10.3389/fimmu.2014.00384

129. Pfefferkorn ER. Interferon gamma blocks the growth of Toxoplasma gondii in human fibroblasts by inducing the host cells to degrade tryptophan. Proc Natl Acad Sci USA. (1984) 81:908-12. doi: 10.1073/pnas.81.3.908

130. Murray HW, Szuro-Sudol A, Wellner D, Oca MJ, Granger AM, Libby DM, et al. Role of tryptophan degradation in respiratory burst-independent antimicrobial activity of gamma interferon-stimulated human macrophages. Infect Immun. (1989) 57:845-9. doi: 10.1128/IAI.57.3.845-849.1989

131. Mackler AM, Barber EM, Takikawa O, Pollard JW. Indoleamine 2,3-dioxygenase is regulated by IFN-gamma in the mouse placenta during Listeria monocytogenes infection. J Immunol. (2003) 170:823-30. doi: 10.4049/jimmunol.170.2.823

132. Slavuljica I, Kveštak D, Huszthy PC, Kosmac K, Britt WJ, Jonjić S. Immunobiology of congenital cytomegalovirus infection of the central nervous system-the murine cytomegalovirus model. Cell Mol Immunol. (2015) 12:180-91. doi: 10.1038/cmi.2014.51

133. Heazlewood CF, Sherrell H, Ryan J, Atkinson K, Wells CA, Fisk NM. High incidence of contaminating maternal cell overgrowth in human placental mesenchymal stem/stromal cell cultures: a systematic review. Stem Cells Transl Med. (2014) 3:1305-11. doi: 10.5966/sctm.2014-0051

134. Bardají A, Steinhoff M, Macete E, Aguado T, Menéndez C. The burden of vaccine-preventable diseases in pregnancy in low-resource settings. Lancet Glob Health. (2016) 4:e152-3. doi: 10.1016/S2214-109X(16)0 0036-X

135. Burton GJ, Sebire NJ, Myatt L, Tannetta D, Wang Y-L, Sadovsky Y, et al. Optimising sample collection for placental research. Placenta. (2014) 35:922. doi: 10.1016/j.placenta.2013.11.005

136. Slyper M, Porter CBM, Ashenberg O, Waldman J, Drokhlyansky E, Wakiro I, et al. A single-cell and single-nucleus RNA-Seq toolbox for fresh and frozen human tumors. Nat Med. (2019) 26:792-802. doi: 10.1038/s41591-020-0844-1

137. Amamoto R, Zuccaro E, Curry NC, Khurana S, Chen H-H, Cepko CL, et al. FIN-Seq: transcriptional profiling of specific cell types from frozen archived tissue of the human central nervous system. Nucleic Acids Res. (2020) 48:e4. doi: 10.1101/602847

138. Wang F, Flanagan J, Su N, Wang L-C, Bui S, Nielson A, et al. RNAscope: a novel in situ RNA analysis platform for formalin-fixed, paraffin-embedded tissues. J Mol Diagn. (2012) 14:22-9. doi: 10.1016/j.jmoldx.2011.08.002

139. Ståhl PL, Salmén F, Vickovic S, Lundmark A, Navarro JF, Magnusson J, et al. Visualization and analysis of gene expression in tissue sections by spatial transcriptomics. Science. (2016) 353:78-82. doi: 10.1126/science.aaf2403

140. Andersson A, Bergenstråhle J, Asp M, Bergenstråhle L, Jurek A, Navarro JF, et al. Spatial mapping of cell types by 
integration of transcriptomics data. bioRxiv [Preprint]. (2019) 2019.12.13.874495. doi: 10.1101/2019.12.13.874495

141. Okae H, Toh H, Sato T, Hiura H, Takahashi S, Shirane $K$, et al. Derivation of human trophoblast stem cells. Cell Stem Cell. (2018) 22:5063.e6. doi: 10.1016/j.stem.2017.11.004

142. Turco MY, Gardner L, Kay RG, Hamilton RS, Prater M, Hollinshead MS, et al. Trophoblast organoids as a model for maternalfetal interactions during human placentation. Nature. (2018) 564:263-7. doi: 10.1038/s41586-018-0753-3

143. Haider S, Meinhardt G, Saleh L, Kunihs V, Gamperl M, Kaindl U, et al. Self-renewing trophoblast organoids recapitulate the developmental program of the early human placenta. Stem Cell Rep. (2018) 11:53751. doi: 10.1016/j.stemcr.2018.07.004

144. Avraham R, Haseley N, Brown D, Penaranda C, Jijon HB, Trombetta JJ, et al. Pathogen cell-to-cell variability drives heterogeneity in host immune responses. Cell. (2015) 162:1309-21. doi: 10.1016/j.cell.2015.08.027
145. Avital G, Avraham R, Fan A, Hashimshony T, Hung DT, Yanai I. scDual-Seq: mapping the gene regulatory program of Salmonella infection by host and pathogen single-cell RNA-sequencing. Genome Biol. (2017) 18:200. doi: 10.1186/s13059-017-1340-x

Conflict of Interest: The authors declare that the research was conducted in the absence of any commercial or financial relationships that could be construed as a potential conflict of interest.

Copyright $(2020$ Hoo, Nakimuli and Vento-Tormo. This is an open-access article distributed under the terms of the Creative Commons Attribution License (CC BY). The use, distribution or reproduction in other forums is permitted, provided the original author(s) and the copyright owner(s) are credited and that the original publication in this journal is cited, in accordance with accepted academic practice. No use, distribution or reproduction is permitted which does not comply with these terms. 